\title{
PELATIHAN ALAT PERINGATAN DINI MANDIRI BENCANA LONGSOR DAN BANJIR PADA KARANG TARUNA KELURAHAN SEMPUR KECAMATAN BOGOR TENGAH
}

\author{
Anwar Mujadin ${ }^{1 *}$, Octarina Nur Samijayani ${ }^{1}$, Suci Rahmatia ${ }^{1}$ \\ ${ }^{I}$ Teknik Elektro, Fakultas Sains dan Teknologi, Universitas Al Azhar Indonesia \\ Jalan Sisingamangaraja Kompleks Masjid Agung Al Azhar Kebayoran Baru Jakarta Selatan 12110 \\ Email Penulis Korespodensi: amujadin@uai.ac.id
}

\begin{abstract}
Abstrak
Menurut Pusat Vulkanologi dan Mitigasi Bencana Geologi (PVMBG) menyebutkan kelurahan Sempur kecamatan Bogor Tengah ditetapkan sebagai kawasan rawan longsor dan Banjir. Kelurahan ini adalah pemukiman penduduk yang berlokasi di daerah tanah lembah bertebing serta di pinggir aliran sungai Ciliwung. Saat ini daerah potensi sering terjadi longsoran adalah daerah RW 05, 06 dan 07 atau berada tepat di area belakang Rumah Sakit Salak sampai Tugu Air Mancur (sempur kaler). Melalui program Prime Public Service 2019 UAI, telah dilakukan pelaksanaan program pemperdayaan masyarakat berbentuk pelatihan alat peringatan dini mandiri bencana longsor dan banjir kepada mitra karang taruna kelurahan Sempur kecamatan Bogor Tengah. Pelatihan dilaksanakan diruang serbaguna kelurahan Sempur, tiap hari minggu jam 13.00 WIB dengan 10 kali pertemuan (3-4) jam. Di setiap akhir sesi pelatihan mitra, kit praktek harus diuji coba dan diimplementasikan langsung pada titik lokasi rawan bencana. Hasil kegiatan telah berhasil merubah mindset mitra (remaja) agar bisa berfikir rasional akan keselamatan diri sendiri maupun orang lain terhadap bencana alam. Perilaku masyarakat pada daerah rawan bahaya mampu dikendalikan secara elektronik melalui alat peringatan dini elektronik buatan mitra setempat. Penyediaan alat peringatan dini dari pemerintah umumnya akan dirusak maupun dicuri. Namun bila alat peringatan dini elektronik buatan masyarakat sendiri, minimal akan dijaga dan dirawat terus.
\end{abstract}

Kata Kunci : Alat pemindai longsor, Pemindai gempa, Pemindai banjir

\begin{abstract}
According to Volcanology and Geological Disaster Mitigation (PVMBG) department, kelurahan Sempur kecamatan Bogor Tengah is designated as an area prone to landslides and floods. Kelurahan Sempur is a residential area located in a cleared valley and along the Ciliwung River. Potential areas for landslides often occur are RW 05, 06 and 07 located behind the Salak Hospital to Tugu Air Mancur. Through UAI Prime Public Service program 2019, has been carried out training program for early warning system landslides and floods devices to youth partners in Sempur. Training has been conducted in multipurpose room kelurahan Sempur office, every Sunday at 13.00 West Indonesia Time, with 10 meetings among 3-4 hours. Each training session, the practice kit must be tested and implemented directly at disaster-prone locations. Training has succeeded in changing the mindset of youth partners so that they can think rationally about the safety of themselves and others against disasters. Community behavior in hazard-prone areas can be controlled electronically through electronic early warning system devices made by youth partners. The Provision of early warning equipment from the government will generally be damaged or stolen. However, if the electronic early warning devices is made by the community itself, They will always be cared for and looked after.
\end{abstract}

Keywords: Landslide Scanners, Earthquake Scanners, Flood Scanner 


\section{PENDAhULUAN}

Bencana hidrometeorologi dapat dikatakan merupakan bencana rutin. Namun dampak kerusakan bencana hidrometeorologi bisa dikatakan relatif kecil bila dibandingkan dengan bencana geologi seperti tsunami akibat gempa bumi (tektonik) maupun gempa letusan vulkanik gunung api (Tun Lin Moe \& Pathranarakul P. 2006).

Di Jawa Barat kota Bogor termasuk kedalam tingkat kerawanan tinggi dengan ancaman bencana gempa bumi, tanah longsor, kekeringan dan cuaca ekstrem. kota Bogor merupakan salah satu kota dengan kondisi geografis perbukitan dengan kontur tanah yang labil. Semakin meningkatnya kepadatan penduduk, kini kota Bogor rentan terhadap berbagai macam potensi bencana seperti bencana banjir, gempa bumi, angin puting beliung, tanah longsor dan ancaman gunung meletus (BNPB 2012).

Kota Bogor yang disebut sebagai kota hujan dialiri beberapa sungai yang permukaan airnya jauh dibawah permukaan kota, yaitu sungai Ciliwung, Cisadane, Cipakancilan, Cidepit, Ciparigi, dan Cibalok, secara umum kota Bogor aman dari bahaya banjir. Namun kota Bogor menjadi salah satu wilayah di Jawa Barat yang ditetapkan sebagai kawasan rawan longsor. Menurut Pusat Vulkanologi dan Mitigasi Bencana Geologi (PVMBG) menyebutkan ada 40 kelurahan di Bogor yang berpotensial rawan longsor yaitu kelurahan Pasir Jaya, Lebak Kantin, Sempur, Empang, Baranagsiang, Balumbang Jaya, dan Cibogor. Masyarakat sempur kaler umumnya berpropesi sebagai pedagang.

Program pengabdian kepada masyarakat yaitu skema Program Pemberdayaan Masyarakat Unggulan Perguruan Tinggi (PPMUPT) mengacu kepada renstra Pengabdian kepada Masyarakat Universitas Al Azhar Indonesia yaitu implementasi teknologi untuk ketahanan (kenyamanan) keluarga dengan memberikan ketrampilan (teknologi) kepada peningkatan produktivitas pemuda-pemudi karangtaruna kelurahan Sempur kecamatan Bogor Tengah.

Adapun fokus pengembangan Pengabdian Kepada Masyarakat unggulan untuk pemecahan masalah tersebut tertuang dalam peta jalan (road-map) Pengabdian Kepada Masyarakat unggulan Universitas Al Azhar Indonesia yang diperlihatkan pada Gambar 1.

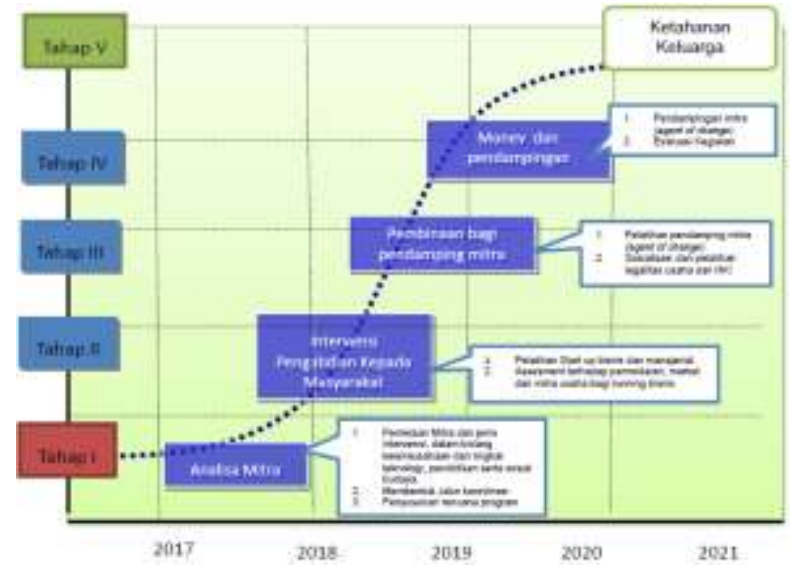

Gambar 1. Peta Jalan (road map) Pengabdian Pada Masyarakat ungulan UAI

\section{Analisa Situasi}

Kelurahan Sempur kecamatan Bogor Tengah adalah pemukiman padat penduduk yang berlokasi di daerah lembah tanah bertebing serta di pinggir aliran sungai Ciliwung. Saat ini daerah potensial sering terjadi longsoran adalah daerah RW 05, 06 dan 07 atau berada tepat di area belakang Rumah Sakit Salak sampai Tugu Air Mancur (sempur kaler). Pada Gambar 2 diperlihatkan sungai Ciliwung berikut akses jalan menuju kelurahan Sempur Tengah.

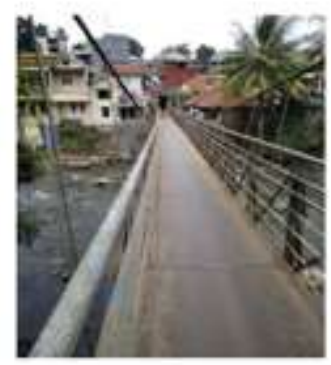

(a)

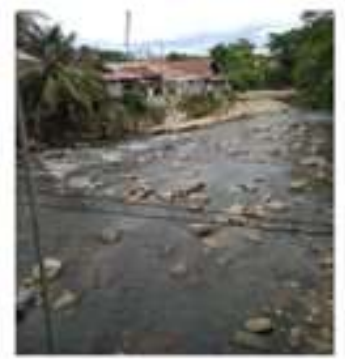

(c)

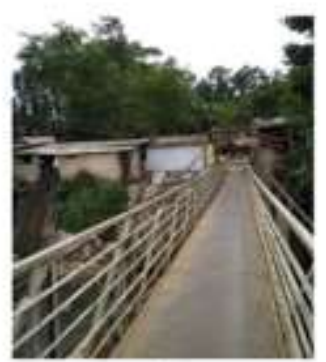

(b)

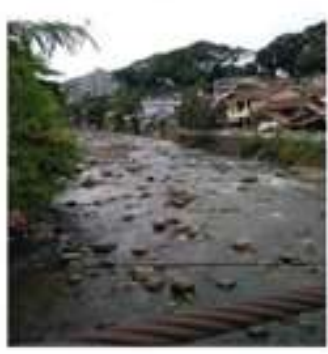

(d)
Gambar 2. Sungai Ciliwung berikut akses jalan menuju kelurahan Sempur: (a)ke-arah timur (b) kearah barat (c) sisi jembatan utara (d) sisi jembatan selatan

Pada Gambar 3 diperlihatkan kontur tanah Sempur Kaler area RW.04. 


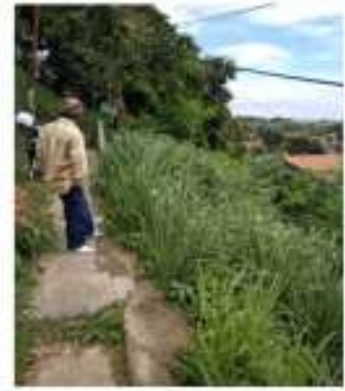

(a)

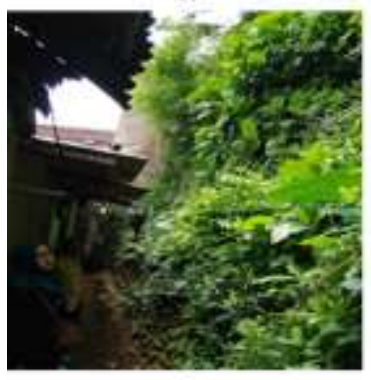

(c)

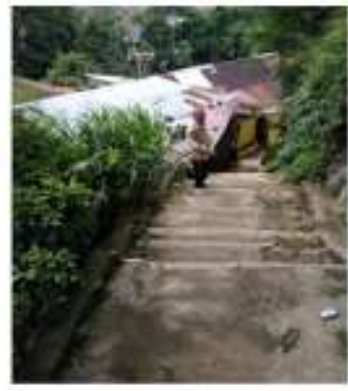

(b)

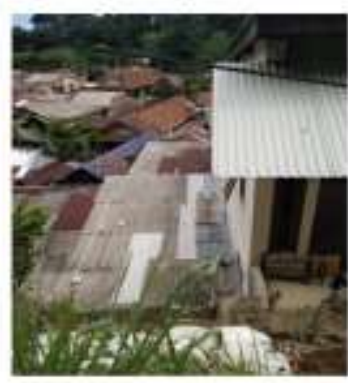

(4)
Gambar 3. Kontur tanah Sempur Kaler area RW.04 Sempur Kaler (a) akses jalan motor (b) akses pejalan kaki (c) rumah penduduk tepat di area tebing (d) rumah di area kontur bawah

\section{Permasalahan Mitra}

Hasil studi pendahuluan yang dilakukan menunjukan bahwa, salah satu permasalahan dari mitra antara lain:

Tabel 1. Hasil studi pendahuluan permasalahan mitra Pokok Keterangan
Masalah

Kelayakan Rumah rawan longsor
huni adalah tidak layak huni. Relokasi menjadi kendala pemda kota Bogor terutama dana ganti rugi.

Alih fungsi Alih fungsi lahan di lahan kawasan tebing menjadi perumahan mengakibatkan pergerakan tanah. Tanah tidak mampu menopang bangunan.

Kurangnya Pendidikan bencana Pendidikan berskala untuk mengurangi Bencana risiko bencana di masa anak-anak menjadi sangat penting. Terutama dalam membentuk perilaku kesiapsiagaan dalam menghadapi bencana.

Kurangnya Belum ada Peringatan dini fasilitas untuk melakukan tindakan peringatan mitigasi bencana.

\begin{tabular}{|c|c|}
\hline $\begin{array}{l}\text { Pokok } \\
\text { Masalah }\end{array}$ & Keterangan \\
\hline $\begin{array}{l}\text { Kurangnya } \\
\text { sosialisasi } \\
\text { aparat } \\
\text { setempat } \\
\text { mengenai }\end{array}$ & $\begin{array}{l}\text { Perlu sosialisasi faktor } \\
\text { yang mengakibatkan } \\
\text { terjadinya gerakan tanah } \\
\text { terutama pada kelerengan } \\
\text { maupun morfologi, kondisi }\end{array}$ \\
\hline longsor. & $\begin{array}{l}\text { geologi, kondisi } \\
\text { keairan/hidroiogi lereng, } \\
\text { perubahan tata guna lahan } \\
\text { maupun kegagalan } \\
\text { konstruksi bangunan. }\end{array}$ \\
\hline
\end{tabular}

\section{Solusi Permasalahan Mitra}

Kesiapsiagaan merupakan tindakan yang dilakukan pada masa pra bencana (sebelum terjadi bencana). Tujuan dilakukannya kesiapsiagaan bencana adalah untuk mengurangi risiko (dampak) yang diakibatkan oleh adanya bencana (Dodon. 2013). Belum adanya mata pelajaran khusus tentang pendidikan lingkungan hidup berbasis bencana dipendidikan formal, telah memberikan andil kurang pekanya kesadaran generasi muda kita untuk peduli pada pemeliharaan dan pelestarian lingkungan hidup disekitarnya (Herdwinarti, F., dan Sudaryono. 2013).

Melalui program Prime Public Service 2019 UAI, telah dilakukan pelaksanaan program pemperdayaan masyarakat berbentuk pelatihan alat peringatan dini mandiri bencana longsor, gempa dan banjir kepada mitra karang taruna kelurahan Sempur kecamatan Bogor Tengah.

\section{METODE PELAKSANAAN}

Berikut adalah tahapan-tahapan rencana pelaksanaan kegiatan Pengabdian Masyarakat yang telah kami lakukan :

\section{Persiapan,}

Persiapan meliputi:

a. Meminta ijin kegiatan pelaksanaan kepada aparat daerah berwenang (RT/RW/Lurah) kelurahan sempur kecamatan Bogor Tengah.

b. Persiapan pembuatan modul kit praktek divais peringatan dini bencana tanah longsor dan banjir.

c. Pemilihan dan kesiapan perwakilan karang taruna tiap RW sekelurahan Sempur. Tiap perwakilan terdiri dari 2 orang dengan menyiapkan minimal 1 laptop (2 laptop sangat efektif). 
d. Kelurahan sempur terdiri dari $7 \mathrm{RW}$, dibuat 7 kelompok (14 orang). Sehingga dipersiapkan 7 modul kit praktek dari perguruan tinggi.

e. Penepatan jadwal kegiatan pelatihan pada mitra.

\section{Pelaksanaan}

Pelatihan dilaksanakan diruang serbaguna kelurahan Sempur, tiap hari minggu jam 13.00 WIB dengan 10 kali pertemuan (3-4) jam. Kit praktek akan menjadi milik mitra (karang taruna). Di setiap akhir sesi pelatihan mitra, kit praktek harus diuji coba dan diimplementasikan langsung pada titik lokasi rawan bencana.

Pertemuan berikutnya akan dilakukan review hasil implementasi kit praktek terpasang dilapangan dari pertemuan sebelumnya. Tim pelaksana akan menilai kelompok (RW) mana yang paling optimal dalam pemasangan kit praktek peringatan dini bencana tersebut.

\section{Pengawasan Pra Pelatihan.}

Pengawasan pra Abdimas (pelatihan) akan dilakukan secara berkala minimal 1 bulan sekali dengan melibatkan mahasiswa Teknik Elektro dengan tugas tambahan dari mata kuliah tim pelaksana dosen. Laporan tugas mahasiswa akan menunjukan skala kepedulian tanggap darurat bencana alam disaster preparedness pada kelurahan Sempur kecamatan Bogor Tengah.

\section{HASIL DAN PEMBAHASAN}

Kegiatan dihadiri oleh 14 orang Taruna Karya (mitra) perwakilan dari dari 7 Rukun Warga (RW) kelurahan Sempur kecamatan Bogor Tengah. Pelaksanaan kegiatan telah direncanakan dalam 10 pertemuan dengan agenda seperti yang diperlihatkan pada Tabel 2 berikut,

Tabel 2. Agenda Pelatihan 10 Pertemuan

\begin{tabular}{|c|c|c|c|}
\hline No & Bentuk Pelatihan & Metode & Instruktur \\
\hline 1 & Soldering & Teknis menyolder yang benar & $\begin{array}{c}\text { Anwar Mujadin ST, } \\
\text { MT. }\end{array}$ \\
\hline 2 & $\begin{array}{l}\text { Making printed and circuit } \\
\text { board }\end{array}$ & Cara membuat PCB praktis & $\begin{array}{l}\text { Suci Rahmatia ST, } \\
\text { M.Sc }\end{array}$ \\
\hline 3 & $\begin{array}{l}\text { Belajar pemograman } \mathrm{MCU} \\
\text { Attiny } 45\end{array}$ & $\begin{array}{l}\text { Menggunakan Note Book + } \\
\text { Android (support OTG) }\end{array}$ & $\begin{array}{c}\text { Anwar Mujadin ST, } \\
\text { MT } \\
\text { Indrawan Arifianto }\end{array}$ \\
\hline 4 & $\begin{array}{l}\text { Pemograman }+ \text { Solder } \\
\text { alat peringatan dini Longsor }\end{array}$ & $\begin{array}{c}\text { PCB Subkon, Implementasi } \\
\text { Lapangan }\end{array}$ & $\begin{array}{c}\text { Anwar Mujadin ST, } \\
\text { MT } \\
\text { Indrawan Arifianto }\end{array}$ \\
\hline 5 & $\begin{array}{l}\text { Pemograman }+ \text { Solder } \\
\text { alat peringatan dini gempa }\end{array}$ & $\begin{array}{c}\text { PCB Subkon, Implementasi } \\
\text { Lapangan }\end{array}$ & $\begin{array}{c}\text { Anwar Mujadin ST, } \\
\text { MT } \\
\text { Indrawan Arifianto }\end{array}$ \\
\hline 6 & $\begin{array}{l}\text { Pemograman }+ \text { Solder } \\
\text { alat peringatan dini banjir }\end{array}$ & $\begin{array}{c}\text { PCB Subkon, Implementasi } \\
\text { Lapangan }\end{array}$ & $\begin{array}{c}\text { Anwar Mujadin ST, } \\
\text { MT } \\
\text { Indrawan Arifianto }\end{array}$ \\
\hline 7 & $\begin{array}{l}\text { ESP } 32 \text { WIFI Module } \\
\text { Aplication }\end{array}$ & $\begin{array}{l}\text { Pemindai sensor melalui } \\
\text { webserver }\end{array}$ & $\begin{array}{l}\text { Anwar Mujadin ST, } \\
\text { MT } \\
\text { Indrawan Arifianto }\end{array}$ \\
\hline 8 & Android User Interface & Blynk Aplication & $\begin{array}{l}\text { Anwar Mujadin ST, } \\
\text { MT } \\
\text { Indrawan Arifianto }\end{array}$ \\
\hline 9 & Draft paten & $\begin{array}{l}\text { Teknis penulisan paten } \\
\text { kekayaan intelektual }\end{array}$ & $\begin{array}{c}\text { Octarina } \\
\text { Nursamijayani ST, } \\
\text { M.Sc }\end{array}$ \\
\hline 10 & $\begin{array}{l}\text { Pendaftaran Toko online } \\
\text { (Tokopedia/Bukalapak) }\end{array}$ & $\begin{array}{l}\text { Jualan online alat peringatan } \\
\text { dini }\end{array}$ & Roqy Dinak ST \\
\hline
\end{tabular}


Pada awalnya kesepakatan pelatihan dilaksanakan tiap hari sabtu jam 8.00 pagi, namun ada beberapa anggota mitra yang sudah bekerja termasuk masuk bekerja pada hari sabtu. Hari minggu juga demikian beberapa mitra keberatan karena biasanya hari minggu pagi digunakan berolah raga bahkan baru bangun tidur karena tadi malam dipakai untuk "malam mingguan". Suara mayoritas ternyata mitra bersedia kumpul tiap hari minggu jam 13.00 WIB.

Pertemuan pertama dilakukan briefing perkenalan mengenai apa itu bencana, efek yang ditimbulkan, dan upaya penangulangan bencana dengan early warning system. Pemaparan dilakukan secara oral maupun dengan tayangan video yang diunduh dari youtube.

Mitra sangat antusias dengan early warning system, dan menyadari bahwa saat ini penanganan bencana di Indonesia sebagian besar berfokus pada kegiatan pasca bencana (post event) berupa emergency response dan recovery daripada kegiatan sebelum bencana berupa disaster reduction/mitigation dan disaster preparedness. Padahal, jika fokus perhatiannya lebih besar pada kegiatan-kegiatan sebelum bencana, dapat diantisipasi agar potensi kerugian (kerusakan) dapat dihindari atau dikurangi melalui manajemen bencana berbasis komunitas dengan memberdayakan masyarakat dalam kesiapsiagaan bencana. Ada satu hal yang mitra sadari bahwa early warning system yang dihadirkan oleh pemerintah justru dicuri maupun dirusak oleh masysrakat itu sendiri yang terkena dampak musibah bencana alam. Gambar 4. diperlihatkan brefing awal.

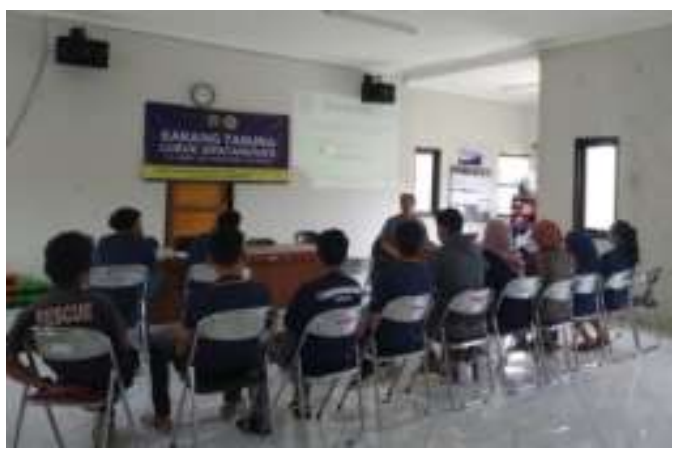

(a)

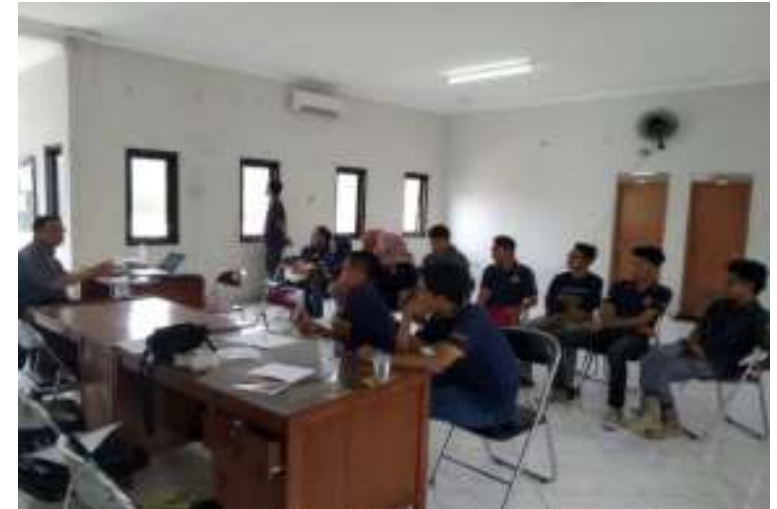

(b)

Gambar 4. Brefing awal kepada mitra (a) sesi perkenalan (b) sesi tanya jawab

Breifing ditutup dengan tanya jawab antara mitra dan tim pelaksana abdimas, kemudian dilanjutkan dengan pemberian tools box pelatihan kepada tiap perwakilan RW. Seluruh tools box menjadi hak milik sepenuhnya mitra. Pada Gambar 5 diperlihatkan tools box pelatihan yang diberikan secara gratis kepada setiap perwakilan.

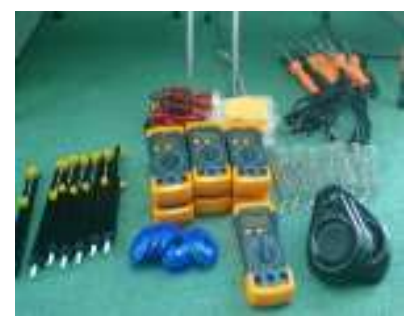

(a)

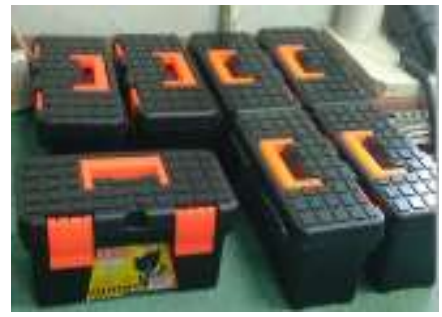

(b)
Gambar 5. Tools box pelatihan (a) tool dan alat ukur (b) box penyimpanan

Minggu - minggu berikutnya diisi dengan pelatihan pelatihan. Anggota mitra dilibatkan dalam pelatihan berbasis elektronika, uniknya rata-rata semua anggota mitra tidak memiliki bacground teknik namun mampu menyelesaikan semua tantangan dari tim pelaksana abdimas dengan sukacita. Sudah banyak universitas lain yang datang pada mitra, umumnya mitra dilibatkan pada kegiatan abdimas sosial dan lingkungan hidup. Baru kali ini mitra dapat tantangan abdimas secara teknis dengan pelatihan membuat alat early warning system buatan mandiri mitra dan langsung diimplementasikan di area bencana mitra. 
Pada Gambar 6 diperlihatkan beberapa pelatihan mitra dalam pembuatan modul electronic early warning system .

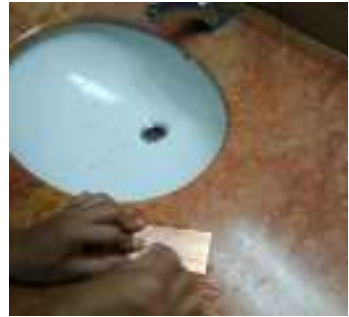

(a)

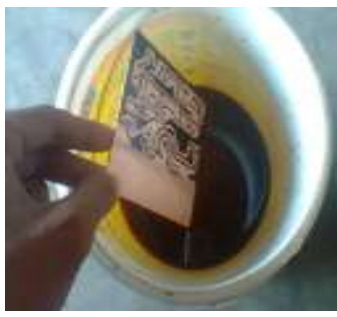

(c)

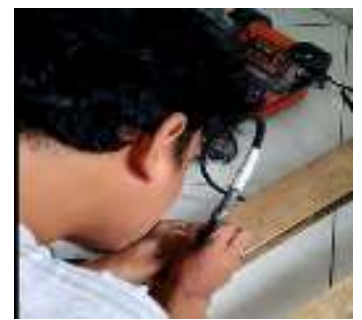

(e)

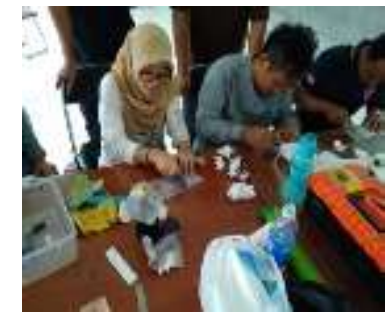

(b)

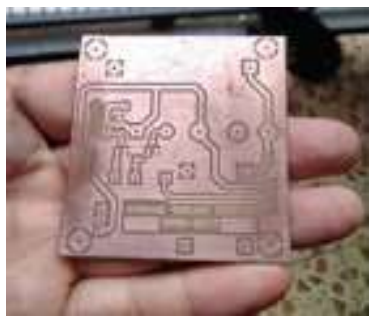

(d)

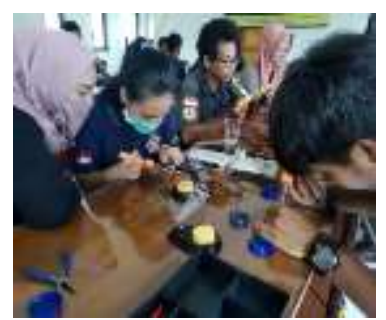

(f)
Gambar 6. Pelatihan mitra dalam pembuatan modul electronic early warning system (a) pembersihan PCB (b) cold layout tranfer (c) eatching (d) hasil eatching setelah dibersihkan (e) pengeboran PCB (f) soldering

Pada kegiatan ini diperlukan banyak kesabaran dari tim pelaksana abdimas, karena umumnya mitra terlalu "gaptek" baik dalam penanganan peralatan elektronik maupun dalam proses pembuatan modul elektronik early warning system. Suatu hal yang unik terjadi pada pelatihan ini, hasil terbaik dari proses pembuatan modul ternyata semua dari kalangan mitra wanita. Penilaian terutama dari keakuratan, kerapihan dan kebersihan hasil solder modul.

Pada Gambar 7 diperlihatkan modul early warning system hasil mitra setelah dirakit dan di solder.

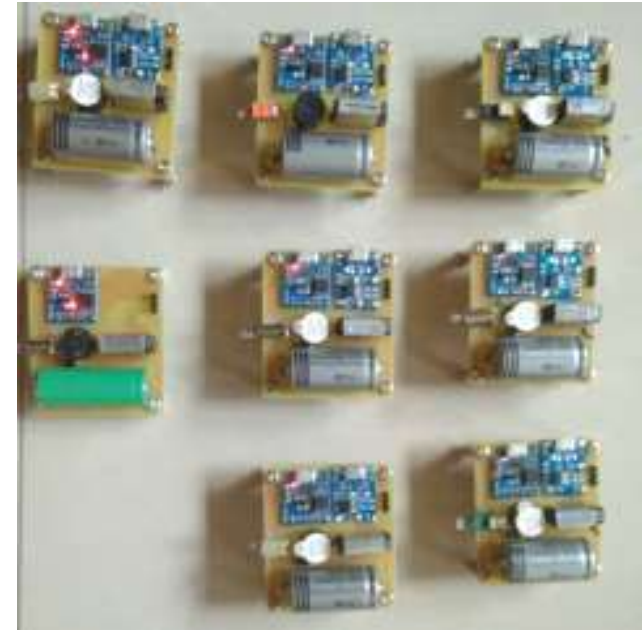

Gambar 7. Modul early warning system hasil mitra setelah dirakit dan di solder.

Modul early warning system ini dibuat secara universal (multi guna) baik digunakan sebagai peringatan dini bencana banjir maupun tanah longsor. Modul ini berbasis mikrokontroler dengan fitur: dua masukan dari saklar digital, satu keluaran buzzer (bunyi) dan satu lampu LED indikator. Mitra diwajibkan membuat program dengan kreasi sendiri namun bunyi buzzer digenerate harus satu satu kesepakatan, karena bunyi buzzer merupakan indikator pakem suara bencana yang harus dipahami oleh seluruh warga. Pada Gambar 8 diperlihatkan pelatihan pemograman modul early warning dengan Arduino IDE . (a)

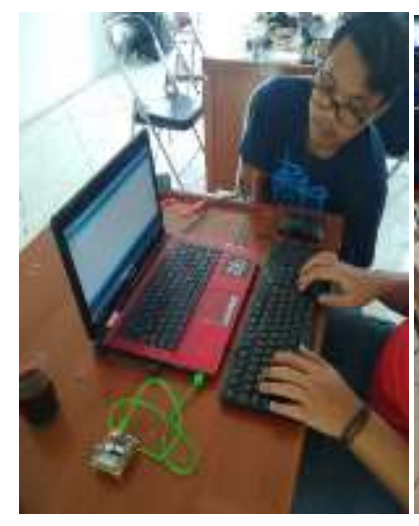

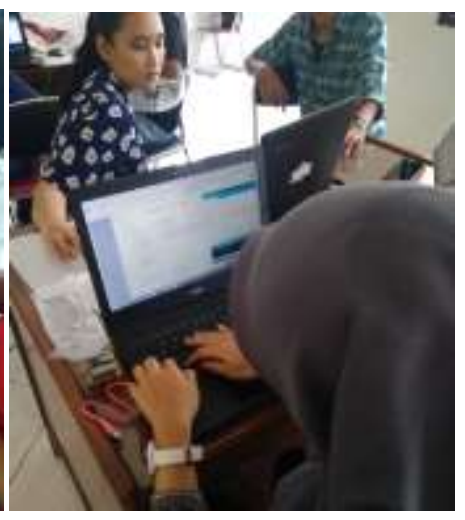

(b)
Gambar 8. pelatihan pemograman modul peringatan dini dengan Arduino IDE (a) plug and play program (b) C++ script writing 
Pelatihan pemograman Arduino pada mitra dilakukan dengan cara plug and play. Mitra disuguhkan pada pilihan script program dengan cukup merubah parameter. Memang awalnya mitra sangat kesulitan terutama dalam memahami bahasa pemograman $\mathrm{C}++$, namun dengan cukup waktu (2 pertemuan) mitra mampu menguasai pemograman $\mathrm{C}++$.

Hasilnya sungguh diluar dugaan peserta mampu menganalisa script program $\mathrm{C}++$ cukup dengan merubah parameter, di-compile $\mathrm{ke}$ mudian di uploading ke modul, bahkan ada yang mampu membuat script sendiri.

Selanjutnya module peringatan dini diimplementasikan pada area rawan longsor dan banjir. Sebelum terjadi bencana sesungguhnya alat peringatan dini mandiri ini disimulasikan dan disosialisasikan kepada warga terutama pada warga yang dekat dengan area bencana.

Kegiatan dilanjutkan dengan pelatihan beberapa hal diluar teknis sesuai dengan agenda sesuai Tabel 2.

Sebagai bahan evaluasi dalam kegiatan ini, para peserta diminta untuk mengisi formulir penilaian arah dan manfaat kegiatan yang telah disiapkan oleh tim pelaksana abdimas. Terdapat 10 pertanyaan dalam kegiatan ini dengan pertanyaan diperlihatkan pada Tabel 3;

Tabel 3. Formulir penilaian arah kegiatan

\begin{tabular}{|c|c|c|c|}
\hline No & Uraian & Pertanyaan & Nilai/Skor \\
\hline 1 & Ide \& Inovasi & Ide orisinil dan inovatif, ide ini belum ada sebelumnya & $\mathbf{A}$ \\
\hline 2 & $\begin{array}{l}\text { Sosial } \\
\text { Entrepreneurship }\end{array}$ & $\begin{array}{l}\text { Kemungkinan besar hasil pelatihan dijadikan produk dan } \\
\text { diterapkan pada daerah (sosial) lainnya. }\end{array}$ & $\mathbf{A}$ \\
\hline 3 & friendship & $\begin{array}{l}\text { Kegiatan ini telah mewujudkan nilai solidaritas antar mitra } \\
\text { (warga) lebih solid lagi. }\end{array}$ & $\mathbf{A}$ \\
\hline 4 & $\begin{array}{l}\text { level of } \\
\text { concern }\end{array}$ & $\begin{array}{l}\text { Produk early warning system mandiri pasti akan dijaga dan } \\
\text { dirawat warga sesuai kebutuhan alat indikasi bencana }\end{array}$ & B \\
\hline 5 & $\begin{array}{c}\text { personal } \\
\text { ability }\end{array}$ & $\begin{array}{l}\text { Kegiatan ini meningkatkan kepercayaan diri, mampu } \\
\text { meyakinkan rekan, sahabat, ataupun investor, bahwa } \\
\text { kegiatan ini bisa dijadikan passive income. }\end{array}$ & B \\
\hline 6 & copy right & $\begin{array}{l}\text { Hasil kegiatan kemungkinan dijadikan sebuah ide besar } \\
\text { dalam pengembangan modul early warning system dan } \\
\text { dijadikan penemuan baru yang di paten kan }\end{array}$ & B \\
\hline 7 & $\begin{array}{l}\text { market } \\
\text { analysis }\end{array}$ & $\begin{array}{l}\text { Membuat market brief, menggambarkan kondisi pasar } \\
\text { secara jelas dan detail, segmen dan target pasar, kesulitan } \\
\text { memasuki pasar, dll }\end{array}$ & B \\
\hline 8 & $\begin{array}{r}\text { knowledge } \\
\text { Improvement }\end{array}$ & $\begin{array}{l}\text { Kegiatan ini perlu dilanjutkan agar pengetahuan mengenai } \\
\text { ilmu mekatronika dan pemasaran bisa ditingkatkan }\end{array}$ & $\mathbf{A}$ \\
\hline 9 & $\begin{array}{l}\text { Financial } \\
\text { plan }\end{array}$ & $\begin{array}{l}\text { Perlu pedampingan untuk memperoleh soft loans dari } \\
\text { Universitas pelaksana abdimas. }\end{array}$ & B \\
\hline 10 & Summary & $\begin{array}{l}\text { Dapat memberikan gambaran mengenai proposal bisnis } \\
\text { yang dibuat secara singkat, konsisten, dan sistematik }\end{array}$ & B \\
\hline
\end{tabular}

Dimana metode penilaiannya dihitung dengan cara manual kemudian di-plot menggunakan Microsoft XL dengan ratarata nilai dihutung sebagai:

\begin{tabular}{ccc}
\multicolumn{4}{c}{ Tabel 4. Range } & Score & Penilaian \\
\hline NILAI & MIN & MAKS \\
\hline A & 80 & 100 \\
B & 60 & 80 \\
C & 40 & 60 \\
D & 20 & 40 \\
E & \multicolumn{2}{c}{$<20$} \\
F & \multicolumn{2}{c}{ Kosong } \\
\hline
\end{tabular}


Rata-rata nilai yang dipresentasikan dalam diagram batang diperlihatkan pada Gambar 9 sebagai berikut:

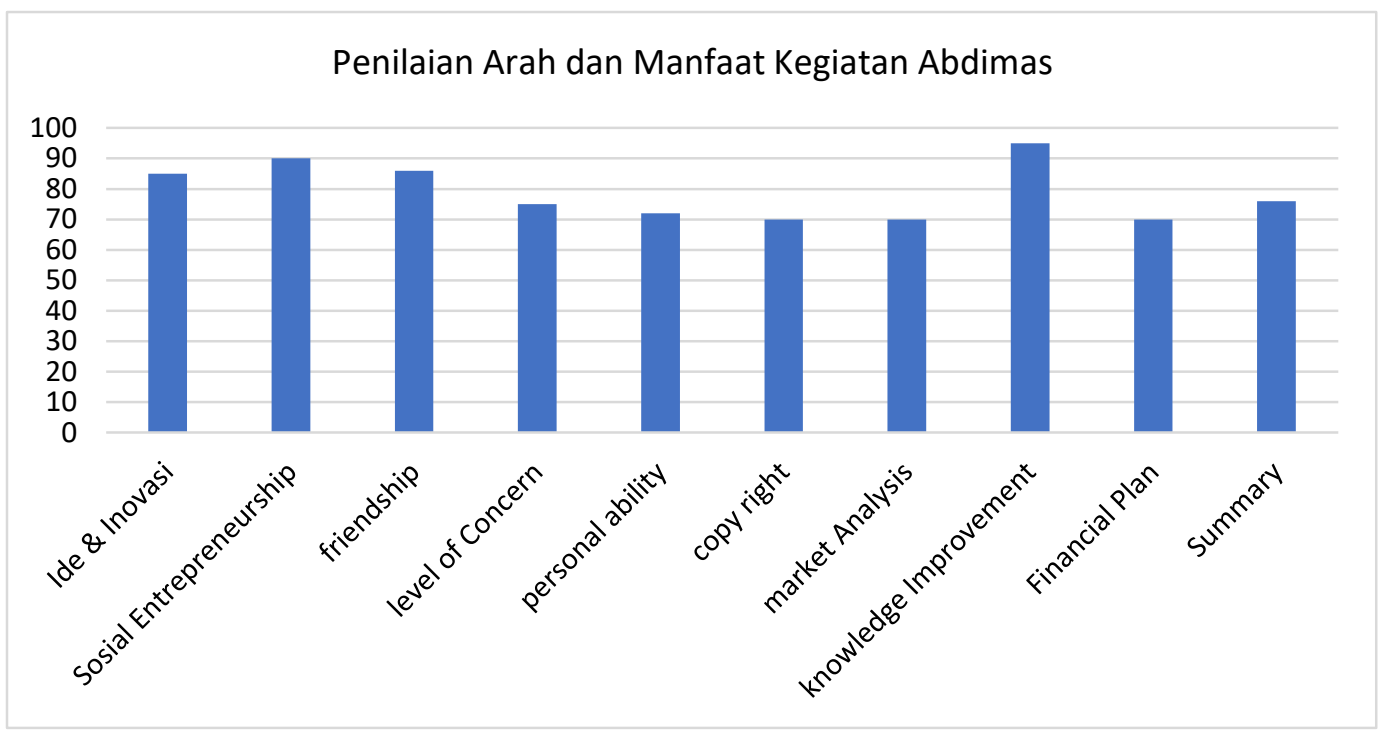

Gambar 9. Diagram batang presentase hasil penilaian arah dan manfaat kegiatan abdimas

Dari diagram batang Gambar 9 terlihat bahwa, mitra menginginkan pelaksanaan abdimas yang bersifat orisinil dan inovatif (ide ini belum ada sebelumnya), dilanjutkan bahwa hasil pelatihan bisa dijadikan produk unggulan selain bisa diterapkan pada area bencana setempat. Mitra menyadari bahwa selama kegiatan terjalin nilai solidaritas antar mitra lebih solid lagi.

Mitra masih merasa khawatir mengenai modul mandiri early warning system mandiri bila telah dimplementasikan, walupun akan dijaga dan dirawat warga sesuai kebutuhan alat indikasi bencana namun tidak menutup kemungkinan alat peringatan dini bencana akan dirusak oleh warga non kelurahan Sempur.

Kegiatan ini meningkatkan kepercayaan diri mitra, sehingga mampu meyakinkan rekan, sahabat, ataupun investor, bahwa produk kegiatan ini bisa dijadikan passive income. Berencana Kegiatan ini akan dikembangkan oleh mitra sebagai produk unggulan warga setempat dengan membuat market brief, tentunya dengan mencari segmen dan target pasar walaupun pasti ada kesulitan memasuki pasar (Wiyono A. 2019).

Mitra menginginkan ada kegiatan abdimas lanjutan, terutama tentang ilmu mekatronika dan pemasaran produk bisa ditingkatkan. Mitra juga menginginkan adanya pedampingan memperoleh soft loans yang dipandu oleh universitas tim pelaksana abdimas. Soft loans tentunya harus dibuatkan proposal terlebih dahulu terutama dalam memberikan gambaran mengenai proposal bisnis yang dibuat secara singkat, konsisten, dan sistematik.

\section{SIMPULAN DAN SARAN}

Tejadi kontradiktif antara anak dan orang tua, terutama mengenai tanggap darurat bencana alam. Orang tua lebih sulit diperingatkan akan bahayanya berada dipemukiman dekat dengan lereng longsoran atau aliran sungai Ciliwung kelurahan Sempur kecamatan Bogor Tengah. Sementara anak (mitra, karang taruna) masih mau dibina dan diperdayakan. Pelatihan ini sebenarnya adalah merubah mindset para remaja agar bisa berfikir rasional akan keselamatan diri sendiri maupun orang lain. Pelatihan ini akan memberikan kontribusi positif kepada orang tua mereka bahwa bila ada sinyal peringatan dini bencana alam, harus segera bertindak tanpa menunggu aparat perintah.

Perilaku masyarakat pada daerah rawan bahaya mampu dikendalikan secara elektronik melalui alat peringatan dini elektronik buatan mitra (remaja) setempat. Penyediaan alat peringatan dini dari pemerintah umumnya akan dirusak maupun dicuri. Namun bila alat peringatan dini elektronik buatan masyarakat sendiri minimal akan dijaga dan dirawat terus.

Kegiatan abdimas ini menghasilkan produk, 
bisa dijadikan kewirausahaan sosial dan dijadikaan produk unggulan anak-anak remaja setempat sebagai passive income.

Saran, untuk mengoptimalkan hasil pelatihan kegiatan abdimas ini perlu diiringi secara konprehensif dengan pendekatan ilmu fisiologi dari universitas tim pelaksana abdimas. Terutama untuk anak pra remaja (SD-SMP) yang perlu sejak dini diberikan pelatihan tanggap darurat bencana terutama dalam kesiapan mental menghadapi bencana.

\section{UCAPAN TERIMA KASIH}

Pengabdian Masyarakat Ini Didukung Oleh Prodi Teknik Elektro Fakultas Sains Dan Teknologi Universitas Al Azhar Indonesia Dari Prime Public Service Grant Internal Lp2m Uai 2019.

\section{DAFTAR PUSTAKA}

Badan Nasional Penanggulangan Bencana (BNPB). (2012). Peraturan Kepala Banda Nasional Penanggulangan Bencana Nomor 1 Tahun 2012 tentang Pedoman Umum Desa/Kelurahan Tangguh Bencana. BNPB
Dodon. (2013). Indikator dan Perilaku kesiapsiagaan Masyarakat diPermukiman Padat Penduduk dalamAntisipasi Berbagai Fase BencanaBanjir. Jurnal Perencanaan Wilayahdan Kota, Vol. 24 No. 2, Agustus 2013, hlm.12

Herdwinarti, F., dan Sudaryono. (2013). Perbedaan Kesiapsiagaan Menghadapi Bencana Ditinjau dari Tingkat SelfEfficacy pada Anak Usia Sekolah Dasar di Daerah Dampak Bencana GunungKelud. Universitas Airlangga. Jurnal Psikologi Kepribadian dan SosialVolume 2, No. 01, Februari 2013

Tun Lin Moe \& Pathranarakul P. (2006).

"An integrated approach to natural disaster management." Disaster Prevention and Management Journal. Vol. 15 No. 3. hal. 396413

Wiyono A. (2019). Kewirausahaan Sosial, Perkembangan, Definisi dan Kesimpulan. Diakses dari https://genagraris.id/see/ kewirausahaan-sosial-perkembangan-definisidan-kesimpulan pada 30 Mei 2019. 